\title{
Addendum
}

\section{Perhydroazulenes - A New Class of Liquid Crystalline Materials}

Henning Hopf,* Zakir Hussain, Rajeev S. Menon, Vitaly Raev, Peter G. Jones, * Ludwig M. Pohl Synlett $2011,1273$.

In this recent publication the following deposition footnote for the X-ray structure determinations was accidentally omitted: Crystallographic data have been deposited with the Cambridge Crystallographic Data Centre as supplementary publications no. CCDC-784418 (9), -784419 (anti-16), -828814 (syn-16). Copies of the data can be obtained free of charge from www.ccdc.cam.ac.uk/data_request/cif. 